\title{
Social institutions mediating seed access in West African seed systems
}

\author{
Kristal Jones $^{\text {a* }}$ \\ ${ }^{a}$ National Socio-Environmental Synthesis Center, University of Maryland, 1 Park Place, Suite 300, \\ Annapolis, MD 21401, USA \\ *kjones@sesync.org
}

\begin{abstract}
Contemporary approaches to market-oriented agricultural development focus on increasing production and economic efficiency to improve livelihoods and well-being. For seed system development, this has meant a focus on seed value chains predicated on standardized economic transactions and improved variety seeds. Building formal seed systems requires establishing and strengthening social institutions that reflect the market-oriented values of efficiency and standardization, institutions that often do not currently exist in many local and informal seed systems. This paper describes and analyzes efforts to develop formal seed systems in Sahelian West Africa over the past 10 years, and identifies the impacts for farmers of the social institutions that constitute formal seed systems. Using qualitative and spatial data and analysis, the paper characterizes farmers' and communities' experiences with seed access through the newly established formal seed system. The results demonstrate that the social and spatial extents of the formal and informal seed systems are extended and integrated through social institutions that reflect values inherent in both systems. The impacts of current market-oriented agricultural development projects are, therefore, more than in the past, in part because the social institutions associated with them are less singular in their vision for productive and economic efficiency.
\end{abstract}

Key words: seed systems, social institutions, West Africa, agricultural development

Citation: Jones K. 2017. Social institutions mediating seed access in West African seed systems. FACETS 2: 998-1014. doi: 10.1139/ facets-2017-00 19

Editor: Wenda K. Bauchspies

Received: February 21, 2017

Accepted: August 21, 2017

Published: December II, 2017

Note: This paper is part of a Collection titled "Social Dimensions of Rural African Agriculture, Food, and Development".

Copyright: (c) 2017 Jones. This work is licensed under a Creative Commons Attribution 4.0 International License (CC BY 4.0), which permits unrestricted use, distribution, and reproduction in any medium, provided the original author(s) and source are credited.

Published by: Canadian Science Publishing

\section{Introduction}

The contemporary dominant discourse of market-oriented agricultural development overwhelmingly champions the combinatory power of scientifically and economically efficient approaches to agricultural production, framing them as a preferable and inevitable evolution from "unimproved", non-market-based inputs and systems (Toenniessen et al. 2008; Pingali 2010). Although the intentions of market-oriented agricultural development programs, especially those led by public and non-governmental organizations, focus on improving livelihoods and food security for the poor, the emphasis on yield gaps and related inefficiencies suggests a narrow view of "progress" that often does not relate to complex and varied local realities (Pingali and Rosegrant 1995; Pradhan et al. 2015). This can lead to an either (or) of current and changing agrarian systems, in which traditional and adaptive actions by farmers and communities are evaluated based on whether or not they engage with economic arrangements and technologies like the improved variety seeds that have characterized the modern, post-Green Revolution period of agricultural development. For example, the value chain approach to seed system development that derives from this discourse seeks to integrate seed systems at various scales by building social institutions that facilitate production and economic efficiency for 
households and communities who have not historically engaged with market mechanisms (Badstue et al. 2002; Louwaars and de Boef 2012).

In Sahelian West Africa over the past 10 years, market-oriented approaches to seed system development have emphasized the establishment or expansion of formal seed markets and private seed enterprises to disseminate improved varieties of sorghum and pearl millet, local cereal grains not included in previous agro-input market development (Siart 2008; Smale et al. 2008; Van Mele et al. 2011). Because of the social role played by seeds, the shift toward formal seed markets and improved varieties challenges existing configurations of seed systems, and provides an important case study of how peasant agriculture adapts to and incorporates new economic and agronomic realities into existing seed systems and the social institutions that constitute them. In this paper, I combine qualitative and spatial data to build empirical understanding of the logic and internal organization of contemporary Sahelian seed systems. I refer to social institutions (also called social infrastructure) as material socio-economic spaces defined by standardized norms and assumptions (Granovetter 1985; Ostrom and Ahn 2001; Pretty et al. 2011). The findings presented here suggest that the social institutions that underpin market-oriented agriculture generate varied and non-uniform outcomes for the individuals and communities engaged with them. Based on diverse social priorities and values in the region, farmers and communities are engaging with new seed value chains in ways that allow for diversification and integration between their existing social institutions and the new institutions being established through market-oriented development projects.

At a general level, seed systems are defined as "a set of market and non-market institutions that govern farmers' access to and use of seeds, and of the genetic resources held therein" (Lipper et al. 2010, p. 5). Seed systems are often differentiated as either formal or informal, categories that become increasingly complex with the inclusion of new actors and institutions in the agricultural development field. Contemporary definitions of formal seed systems generally relate formality to the value chain approach, where "formal systems are purposively composed of separate activities to provide new varieties, maintain their purity, certify the seeds and distribute them to farmers, usually through officially recognized seed outlets" (Bentley et al. 2011, p. 8). Some descriptions are more explicit about the centrality of standardized improved varieties and markets to formal seed systems, whereas others emphasize that formal seed systems operate at the national or international level (rather than at the community or regional level) (Bishaw and Turner 2008; Berg 2009; Lipper et al. 2010). Informal seed systems-also often referred to as traditional or local-have in the modern era consistently been defined as "everything else" that is not formal and standardized (Sperling and McGuire 2010). The contemporary legacy of the Green Revolution is evident in the social institutions that make up formal and informal seed systems. Formal improved varieties can be accessed only through sales (or official aid donations) from organizations that produce seeds using formal scientific processes, and formal sales can only include seeds certified through official government offices and processes (Kloppenburg 2010; Lipper et al. 2010). Informal seed systems then include all other types of seed production and identification-traditional, creolized, and socially certified-and all other kinds of transactions, including those in local markets with cash, through non-cash exchanges, and as gifts (Almekinders et al. 1994; Bishaw and Turner 2008; Sperling and McGuire 2010).

The value chain approach that is common in market-oriented agricultural development provides an additional, explicitly spatial component to seed systems and the institutions that constitute and govern them, highlighting the patterns of production and reproduction that can occur at many different scales (Jones 2017). Developing formal seed value chains in local and national contexts, especially those in sub-Saharan Africa, without an extensive history of modern agricultural development has necessitated new institutional arrangements that embody the values of production and economic efficiency (Tripp 2001; Coulibaly et al. 2008; Bellon et al. 2010; Scoones and Thompson 2011). The 
establishment of local farmer organizations has facilitated connections between formal plant breeding programs and informal seed systems by connecting farmers to demonstrations and field trials meant to provide information about the use and re-use of improved varieties, as well as by providing farmer seed producers with training and technical support (Weltzien et al. 2003; Bishaw and Turner 2008; Coulibaly et al. 2008). Agrodealers, meanwhile, function as a specific link in the seed value chain, selling certified seeds and expanding the reach of national and international private seed suppliers into formerly underserved rural and remote areas of many countries (Dalohoun et al. 2011; Scoones and Thompson 2011). The value chain approach to seed system development that focuses on building these and related social institutions is more flexible than earlier versions of market-oriented agricultural development, in large part because the institutions are locally based and can be integrated into other local social institutions. At the same time, because production and economic efficiency still provide the foundational values of these formal seed systems, the social institutions that constitute them remain largely prescriptive, even if more inclusive (Richards et al. 2009).

\section{Materials and methods}

\section{Setting}

The research presented here was conducted from 2010 to 2013 in the Sahelian West African countries of Mali, Niger, and Burkina Faso. There are relatively small differences across countries and sites, but in general Sahelian West Africa is considered a continuous region based on the continuity of most of the defining characteristics of the natural and social settings (Moseley 2008). Agricultural systems in Sahelian West Africa are shaped by characteristics of the natural and social settings, which create both constraints and opportunities. Because of the semi-arid climate and lack of irrigation for the vast majority of farmers in the region, agricultural production is limited in scope and diversity by rainfall. Pearl millet and sorghum are planted much more extensively than any other cereal crops because of their biological and social adaptation throughout the region. Landraces make up the vast majority of the area planted with pearl millet and sorghum; Alene et al. (2011) estimated that in 2011, <20\% of the area for either crop was planted with improved varieties. Where improved varieties are used, they are almost entirely conventionally bred (without the use of genetic engineering) and openpollinated varieties that come from the national and international agricultural research centers, although research has increasingly focused on hybrid varieties (Haussmann et al. 2012). In the data presented here, all improved varieties are open-pollinated and therefore able to be saved.

Across West Africa, there is a current emphasis on formal market-oriented seed system development, with extensive investments in national-scale private seed enterprises in Mali and Niger (Dalohoun et al. 2011), agrodealer training in Mali (Scoones and Thompson 2011), and the strengthening of seed production laws and farmer organizations across the region (Coulibaly et al. 2008; Smale et al. 2008; ISPC 2012). Traditional or local seed systems in Sahelian West Africa are best defined not in relation to formal seed systems, but instead as consisting of a range of activities embedded within social relations. A consistent theme of local seed systems is the social injunction against purchasing or selling seeds in many areas of Sahelian West Africa (Smale et al. 2008). Traditional seed systems and the social institutions associated with them are facilitated instead by sharing, kinship obligation, and a cultural understanding of seeds as a social good (Siart 2008; Smale et al. 2008). As farmer organizations and local agrodealer outlets are established and strengthened, however, new institutional configurations and connections among local informal and formal seed systems are starting to emerge (Diakité et al. 2008).

Farmer organizations have a long history in the Sahel and have provided an important link between formal agricultural research and development projects and affected rural communities (Coulibaly et al. 2008; Diakité et al. 2008). Farmer organizations were originally created through a variety of 
interactions, including support from national governments and international NGOs, and all of the organizations employ local farmers as technicians to spread and teach new technical information, which increasingly includes new seeds. Seed systems development projects provide marketing and commercialization training to these organizations in an effort to build a local base for seed markets. This shift from investing in farmer organizations to develop local informal seed systems to a focus on market-oriented seed systems, but with the goal of keeping some of the profits at the level of the farmer organization, reflects the additional value in contemporary value chain development of localized economic impact. A similar value is reflected in the creation and support of agrodealers' skills and shops, many of whom have been supported by large international donors as part of projects focused on building capacity for national-level value chains and the economies of scale that can accompany them (Dalohoun et al. 2011). Agrodealers are generally based in rural market towns but are not necessarily from the area, and they represent a discrete step in a value chain in which seed production, certification, packaging, and distribution are all activities carried about by different actors and within distinct institutional contexts.

\section{Research questions}

1. Does the establishment of the social institutions that constitute formal market-oriented seed systems support farmers' access to seeds?

2. Do individual farmers and rural communities engage with both formal market-oriented seed systems and informal seed systems?

The specific hypotheses posited by the value chain approach to seed system development suggest that (1) the establishment of the social institutions that constitute formal market-oriented seed systems will support new and increased access to seeds; and (2) that farmers will choose to engage with the formal seed system over the informal because of the standardized, reliable, and impersonal characteristics of the social institutions that constitute the formal seed system. The research questions that frame this project, therefore, are broad, and reflect the assumptions inherent in the hypotheses of the market-oriented development approach.

\section{Sampling and data collection}

This project utilized a concurrent, multilevel mixed methods sampling design, where a single sample is generated using both purposive and probabilistic techniques (see Teddlie and Yu 2007). I used purposive cluster sampling to identify six research sites, two in each country, across Mali, Burkina Faso, and Niger. I then defined sample strata and used random sampling to select individual farmers, from whom I gathered quantitative and qualitative data to provide consistency and the ability to both triangulate and test hypotheses with the data. This paper presents an analysis of (1) qualitative data, with the individual farmer as the unit of observation and analysis; and (2) spatial data, with the village as the unit of observation and the research site as the unit of analysis.

A site is defined as the localized area, consisting of dozens of villages, in which a single farmer organization that produces and sells improved variety seeds works and has members. The radius of influence from an organization's central office varies from 50 to $100 \mathrm{~km}$ or more. The sample sites were chosen through a purposive sampling that accounted for different histories of work with NGOs, the feasibility of travel to the site, and past social science research conducted there (to avoid research fatigue for communities). Once the sites were selected, the theoretical population of interest for this study became all farmers within the service area of the social institutions. This study used a purposive stratified sampling frame based upon three strata of the overall population, as follows: those farmers who purchased improved variety seeds from farmer 
organizations or from agrodealers, and those farmers who received improved variety seeds through exchanges or gifts from original buyers. After the 2010 season (during which there were only first-order seed purchasers), I used snowball sampling to follow the exchange of seeds, interviewing farmers who received improved seeds from those who originally bought them; that is, I began to snowball to "second-order" farmers (Biernacki and Waldorf 1981). Table 1 shows the distribution of individuals across strata for the overall sample, which was used for both qualitative and quantitative analysis.

Following Small's (2011) terminology, I used a concurrent mixed-data collection design to maximize the limited time in the field and to minimize demands placed on research participants. I gathered qualitative, quantitative, and spatial data at the same time, using multiple techniques to gather the data. For much of the qualitative and quantitative data, I conducted semi-structured interviews with farmers who have bought improved varieties of seeds as well as those who received improved variety seeds from others. These interviews asked questions about how farmers perceive their seed networks and markets-where they receive information and materials, how and why they access them, and the meaning and impact of engaging with different social institutions that constitute their contemporary seed system. I also asked specific questions about changes they have seen in information and seed sources, why those changes have come about, and how they have experienced the impacts of these changes.

Table 1. Sample size by site, stratum, and year (total $n=513$ ).

\begin{tabular}{|c|c|c|c|c|c|c|}
\hline \multirow[b]{2}{*}{ Field sites } & \multicolumn{2}{|c|}{2010} & \multicolumn{2}{|c|}{2011} & \multicolumn{2}{|c|}{2012} \\
\hline & $\mathbf{M}$ & $\mathbf{F}$ & $\mathbf{M}$ & $\mathbf{F}$ & $\mathbf{M}$ & $\mathbf{F}$ \\
\hline \multicolumn{7}{|l|}{ Siby, Mali } \\
\hline Buyer & 19 & 3 & 27 & 12 & 23 & 14 \\
\hline Receiver & - & - & 0 & 1 & 12 & 6 \\
\hline \multicolumn{7}{|c|}{ Dioila, Mali } \\
\hline Buyer & 47 & 0 & 36 & 3 & 33 & 2 \\
\hline Receiver & - & - & 3 & 0 & 0 & 5 \\
\hline \multicolumn{7}{|c|}{ Dédougou, Burkina Faso } \\
\hline Buyer & 73 & 6 & 66 & 8 & nd & nd \\
\hline Receiver & - & - & 3 & 1 & nd & nd \\
\hline \multicolumn{7}{|c|}{ Serkin Haoussa, Niger } \\
\hline Buyer & 36 & 15 & 65 & 36 & 47 & 35 \\
\hline Receiver & - & - & 5 & 27 & 20 & 31 \\
\hline \multicolumn{7}{|c|}{ Bokki, Niger } \\
\hline Buyer & 22 & 1 & 27 & 3 & 23 & 2 \\
\hline Receiver & - & - & 1 & 0 & 9 & 1 \\
\hline Total $^{a}$ & 197 & 25 & 233 & 93 & 167 & 96 \\
\hline
\end{tabular}

Note: nd, no data because of political instability.

${ }^{a}$ Totals for each year sum to more than the overall sample total due to the inclusion of individuals in a panel data set who were interviewed all three years. 
In addition to semi-structured interviews, I conducted group meetings in 2010 and 2011 in six villages in Burkina Faso and six in Niger to gather qualitative and spatial data. During the meetings, we discussed individuals' experiences of seed networks and how people share agricultural information and inputs. To help elucidate experiences in a different medium and to gain spatial data, I also used participatory mapping techniques (see Fortmann 2008). Each year we drew a map of the community seed networks, depicting the places from where the village received seeds and to where they sent seeds. In 2011, we compared any changes from the previous year, which led to further discussion of the changes in seed systems at the village and regional level. Finally, I used a GPS unit to record the coordinates of every village I visited, to create maps that depict different aspects of the seed system as well as changes over time. In addition to primary data collection, I used a range of secondary data sources to supplement the spatial data, including the distribution of field trials in each area, and a database of geographic coordinates for every village in Mali, Burkina Faso, and Niger, both of which were provided to me by local colleagues.

All research efforts described here were undertaken after receiving approval from the Pennsylvania State University Institutional Review Board (\#41352). The research was conducted in conjunction with both an international agricultural research center and national agricultural research service colleagues, but none of them had clear IRB policies and procedures so I utilized those of my home institution. Due to literacy and language constraints, I requested and received approval for a verbal consent process, and I developed a consent script that was read to each participant in a private setting prior to being interviewed. All of the raw materials (paper surveys and notes, audio recordings, and photographs) and digital files are kept in a locked file drawer or on a password-protected hard drive. All personally identifying information was excluded from the digital files, and each respondent and village was given an identification number.

\section{Data analysis}

I used a sequential approach to mixed-data analysis, first analyzing the qualitative data from interview transcripts and then analyzing spatial representations of seed systems based on indicators of social institutions identified through the coding process (Creswell and Plano-Clark 2011). For qualitative data analysis, I used horizontal coding to lay out the breadth of experience and perceptions associated with formal seed markets and improved variety seeds, to have as complete an understanding of the field of experience as possible (Coffey and Atkinson 1996; Creswell 2007). I started with the broad categorizations of the institutions and characteristics that distinguish formal and informal seed systems from one another, and then through an iterative process identified themes that characterize the types of access that the distinct social institutions create as well as the impacts that access has on individual farmers and communities. The data (quotations) are presented as representative of a specific code or theme within the categories that I identified throughout the process of initial data analysis, and the data are often not attributed to particular individuals because they are representative of a common experience expressed by several of those interviewed (see Weiss 1994, for discussion of presenting qualitative data). In addition, the data are presented in single quotation marks rather than double quotation marks, to remain consistent with the multiple layers of translation (from a local language to French to English) necessary to present quotations here in English (Peters 1973; Halai 2007).

I also present visual representations of the spatial and scalar dimension seed systems and the social institutions that constitute them using both hand-drawn maps made by farmers during group meetings in villages, and digital maps made by me. Farmers' hand-drawn maps of informal seed systems suggest a much shorter supply chain than those being instituted by market-oriented development projects, whereas maps of seed saving, sharing, and sales that I generated from my primary data depict the varied spatial extents and points of overlap between informal and formal seed systems. Combining 
qualitative and visual data allows me to draw connections between individual access decisions and their impacts, and the role that the social institutions play in facilitating or limiting farmers' engagement with different types of seed systems.

\section{Results}

The social institutions of informal seed systems in Sahelian West Africa emphasize sharing within families and communities, and economic arrangements that are negotiated in local marketplaces. In contrast, market-oriented agricultural development proposes a new set of social institutions for formal seed systems, designed to build value chains that facilitate market access to improved varieties of seeds. Much of the description by farmers of their experiences with the new social institutions and interactions do or do not support access to improved varieties, often by comparing new standardized market exchanges to existing social institutions that provide access to different types of seeds. Farmers' and communities' experiences with farmer organizations and agrodealers in particular, as well as their observations of if and how these new institutions connect to those that constitute informal seed systems, suggest that the impacts of market-oriented seed system development vary by individual and by type of institution.

\section{Does the establishment of social institutions that constitute formal market-oriented seed systems support farmers' access to seeds?}

The social institutions, including farmer organizations, agrodealers, and seed enterprises, that constitute formal market-oriented seed systems are based on a cash economy and standardized economic exchanges of seeds. As farmers experience the new institutions for seed sales as reliable and consistent, many are increasingly interested in formal exchanges as an additional means of buffering against the risks associated with other social institutions like seed sharing and saving. 'In the past, accessing seeds, it was a little complicated. Because if a farmer had seeds, when you asked, he could tell you to wait until he was done with the seeds, and then he'd give to you. But now, there are sales. You can buy directly, and you won't take time'. For some farmers, the knowledge that formal exchanges are an increasingly reliable seed access option means that they have stopped saving seed, 'because they know that when you need seeds, you can find them with [the farmer organization]'. Other farmers see seed sales as a complement to, rather than a replacement for, seed saving: 'She said that she saved a little, and if we don't bring any more, she will plant what she saved'. The major pressure on all social institutions that support seed access, both formal and informal, is the demand of household food needs and the consistent risk that they will not be met. In this way, the presence of standardized seed sales helps buffer against the possibility that a household cannot save seeds because 'during the harvest, there wasn't enough grain, so they just started eating it'. Seed sharing is also difficult because, as one woman in Mali explained, 'she can't save part as seeds, and give them. She also has to eat'. The certainty of formal seed sales, then, can complement the access options available in informal seed systems, and can provide community-level seed security, albeit a conditional security, as formal economic exchanges require always-scarce cash.

The expansion of social institutions that support formal seed systems has also challenged seed sharing arrangements, when the logic of economic exchange begins to supplant other social priorities: 'people asked [for seeds] and she said that they aren't aid, to give to someone ... since she invested money in them, they should buy also'. As one woman in Burkina Faso noted, 'What she's noticed is that there are people who refuse to give seeds for free ... if you want them as gifts, there are people who refuse them, they say they aren't seeds. When you give money, you will have something'. Similarly, some farmers have experienced a change in terms of sharing now that seeds are available for sale: 'before, there was solidarity. People gave seeds, and others exchanged. But now you have to pay'. The cash element of formal economic exchanges presents a challenge in rural areas with little consistent opportunity 
to earn cash. As the value chains for formal seed systems expand and become increasingly institutionalized at every step of the way, many seed producers who work for farmer organizations report no longer giving or selling seeds directly from their fields, instead sending people to the farmer organization's shop so that the shop can 'get more clients and benefit, to attract others'. For the most part, however, farmers in the Sahel increasingly express a dynamic calculation that supports access to seeds through multiple social institutions. A man in Niger sums it up well: 'now there is really a chance, in terms of access to seeds. We can find them here in the shop. If someone doesn't go to the shop, you can find them also with a relative who grew them last year, to get them and replant. There is diffusion'.

By engaging with multiple types of social institutions to access seeds, farmers in contemporary Sahelian seed systems have access to multiple types of seeds. Currently, improved varieties originate almost entirely from local farmer organizations and extra-local institutions that include agrodealers and the seed enterprises for which they work, and seed sales have begun to define types of seeds for some farmers: 'for local varieties, when you want to plant, you bring a quantity to exchange with the variety that you want. And she said that for improved varieties, you pay'. For other farmers, the place a seed was accessed might define the type of seed it is. For landraces, 'they are with relatives, always with relatives or friends'. Improved varieties, on the other hand, are bought 'with the [agrodealer or farmer organization] shop, and in a packet, with information, they explain all of the characteristics'. The linkage between how a seed is accessed and the type of seed is not firm, however, as the formal seed system institutions also link to the informal seed system institutions that create access through seed sharing and seed saving. As one woman in Mali explained, '[the farmer organization] has to stock seeds so that more people can use them. They will plant, and then someone else can ask to try them, and seeds will be diffused. Mostly by exchange'. Many seed producers report that they sell and exchange what are effectively socially certified seeds (with their traits "certified" based on trust) to family and neighbors outside of the institutions of formal seed systems. As one man in Burkina Faso explained, 'Since it is family, it's among us. Sometimes we do exchanges. You bring one or two bot [local measure], and then I give you two bots. Because people don't have the money to buy. If your brother comes and says, I want that variety, you have to exchange'.

\section{Do individual farmers and rural communities engage with both formal market-oriented seed systems and informal seed systems?}

Discussing farmer organizations as local social institutions, some people voiced appreciation for farmer organizations' efforts in seed dissemination, in contrast to previous experiences with development projects that 'created access. And sometime they brought [seeds] late. With local organizations, there are people in the union who hear him', and so specific requests or needs are more likely to be incorporated into the seed system. Village groups, which are generally affiliated with farmer organizations, provide even stronger social networks from which to learn and innovate. One woman in Niger explained that now that there is a village group, 'they have a line, they are informed of new varieties. All about agriculture, they have networks to get information'. The line is not to an outside entity, but to the local input shops, other farmers' fields, and most importantly, shared experience. As social institutions, farmer organizations can create a space for social learning and seed exchanges by supporting field trials, training, and the local production of improved variety seeds.

In describing their appreciation for seed sales by both farmer organizations and agrodealers in local marketplaces, many farmers make the connection between the spatial organization of marketoriented institutions and their relevance to local seed systems. In the past, a farmer might have 'heard seeds talked about, but he had never come across them here'. Instead, to access improved varieties and sometimes even landraces, 'you had to go to town to find them, pay the cost of transport'. Now, however, with the institution of localized points of sale, 'if you need seeds, you don't have to travel. Seed 
sales in local markets allow individuals to observe and make their own seed choices: 'if you go to the market, you pass by and see that people are really interested in this variety. That's why he was motivated also to buy them'. However, many farmers still prefer to receive information from a known source before making decisions about new seeds, and it is here that agrodealers and the seed enterprises they represent are seen as a less trusted source of information than local farmer organizations. 'In the past, information came with the agrodealers, but when you put them with a farmer organization, others will be informed by the radio, and those can buy who are in villages that are around'. Although they both provide access to the formal seed system through seed sales, farmer organizations are both more local and more dynamic social institutions than agrodealers, who are generally seen as solely market actors that exist outside the local milieu. Particularly for women, the local integration of farmer organization representatives creates a bridge to the formal seed system that would not exist through impersonal agrodealers. As a woman in Niger explained, 'Now that there are sales, they don't sell them at a price that the women like. So she gives her money to the [farmer organization] agent, and that's who buys her the variety that she plants'.

As farmers and communities have observed and experienced the development of the social institutions associated with formal market-oriented seed systems, they have begun to engage with them in ways that fit their local social context, creating linkages between the systems through both existing and new social institutions. Maps of local seed systems drawn at the village level capture a visual representation of the social institutions that constitute both informal and formal seed systems in a given research site. Figure 1 presents two such maps drawn by residents of two villages in the Dedougou region of Burkina Faso.

The two maps presented in Fig. 1 depict two different but related aspects of the spatial configuration of contemporary seed systems in the Dedougou research site. The map in panel A shows the social institutions and relationships among them in the newly created formal seed system. The value chain flows in linear fashion from the national agricultural research station in the upper right-hand corner, where new improved varieties are developed, to the farmer organization headquarters in the regional city, Dedougou, where improved variety seeds are sent for certification and packaging. Seeds are then brought to a central village by the local farmer organization representative who lives in the village, and individuals from the villages at the top and bottom of the map come there to buy seeds.
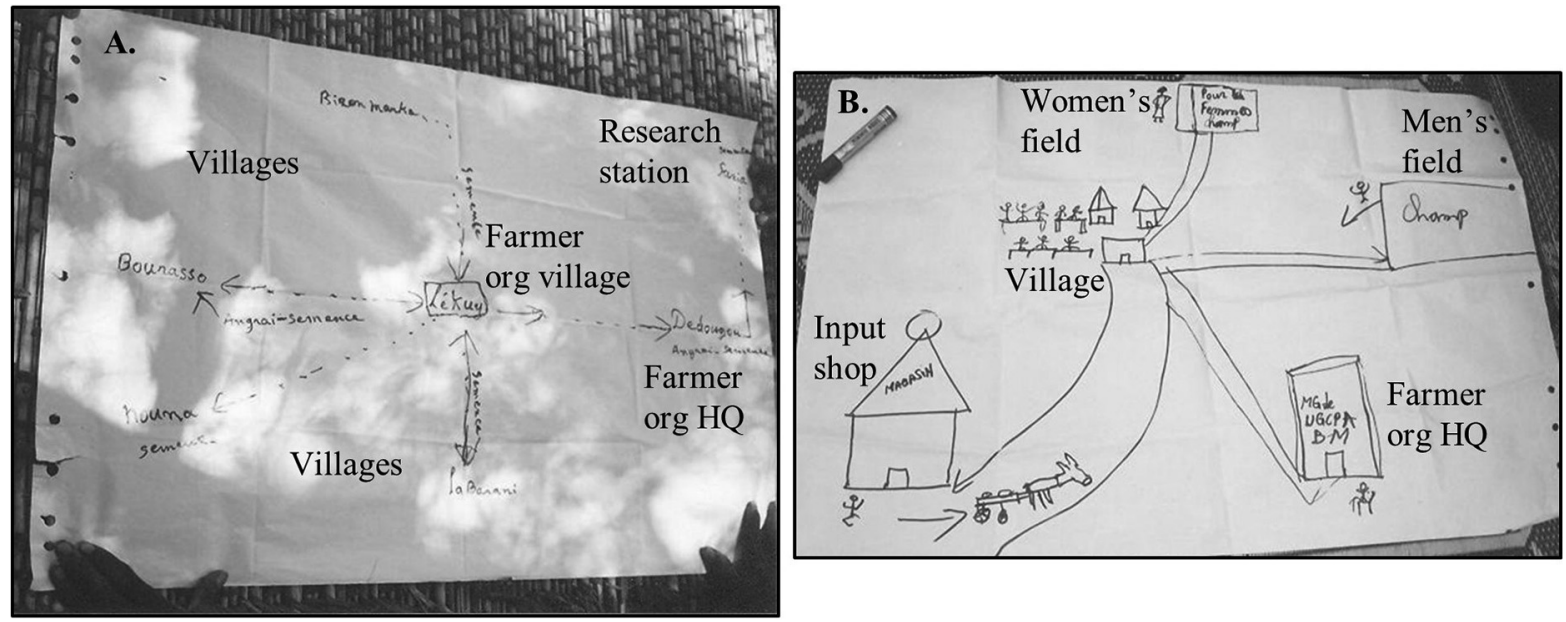

Fig. 1. Village-level seed system maps from the Dedougou region of Burkina Faso. 
Farmers also noted that there are seed producers in the surrounding villages who sell uncertified improved varieties straight from their fields, creating a linkage point between the formal and informal seed systems. While drawing the map in panel B, farmers in a different village in the region told the story of seed movement from the beginning of the season to planting time. The store in lower left-hand corner of the map is a shop run by someone local from the farmer organization. If one person went to get seeds, he would bring them back to the village and call other people together (the group seen in the upper center of the map) to tell them about the seeds and give them some. If his wife asked for some seeds, he would give her a little bit to try in her field. Then the farmer would plant them in his field, at the right. At the end of the season, he would bring some seeds back to the village and save them for next year. If he had some that met the certification requirements, he would also take some to the farmer organization headquarters to sell as seed the following year.

These two maps and their descriptions represent two different ways that improved variety seeds are accessed through the social institutions that constitute the newly established formal seed systems, and how those seeds are then further accessed and changed through the engagement of the social institutions that make up informal seed systems. In both maps, the initial infusion of improved variety seeds comes from an extra-local social institution, an agrodealer shop, or a farmer organization representative. The seed then becomes informal and local in both access and genetic makeup, as it is saved and circulated within and among villages over multiple years. Social institutions that constitute informal seed systems, including uncertified seed sales, seed banks, and kinship ties, facilitate this movement and change in the characteristics of seed access and seed type. Farmer organization members, as both seed producers and seed sellers, are the primary point of overlap and interconnection between the seed systems. The result is an interconnection of formal and informal seed systems based on varied local values and realities, rather than the dominance of a single formal seed value chain with linear movement of seeds each year (as is the goal of market-oriented agricultural development).

The maps presented in Fig. 1 are the result of village-level discussions about seed systems and how farmers are engaging with the new formal seed systems being established in Sahelian West Africa. The maps presented in Fig. 2 draw on results from the full sample of farmers who accessed improved variety seeds from 2010 to 2012 through purchases, exchanges, and saving. The Dedougou, Burkina Faso region is compared with the Dioila, Mali region, to highlight the similarities and differences in how the institutions that constitute the formal and informal seed systems in each region are integrated and impacting overall seed access.

The two maps presented in Fig. 2 provide a visual representation of the social institutions that constitute formal and informal seed systems in contemporary Sahelian West Africa, and how their spatial integration does or does not facilitate different types of access to improved variety seeds. The maps of seed movement in both the Dedougou region of Burkina Faso and the Dioila region of Mali reflect the same themes seen in the two hand-drawn maps presented in Fig. 1. Farmer organization representatives are integral to the movement of improved variety seeds from the regional headquarters into their own villages and villages directly surrounding their own. The radial pattern of seed sales in the maps in Fig. 2 depicts the linear value chains that are characteristic of the formal market-oriented seed systems currently being established in each region. In addition, the points of integration between the formal and informal seed systems, described and depicted in panel B of Fig. 1, are also clearly visualized in the maps in Fig. 2. In almost every village to which seeds were sold in both Burkina Faso and Mali farmers reported saving those seeds for use the following year, and in most villages to which seeds were sold farmers report sharing seeds the following year with others in their own villages or even further afield. Seed sharing includes exchange and gifts of seed 

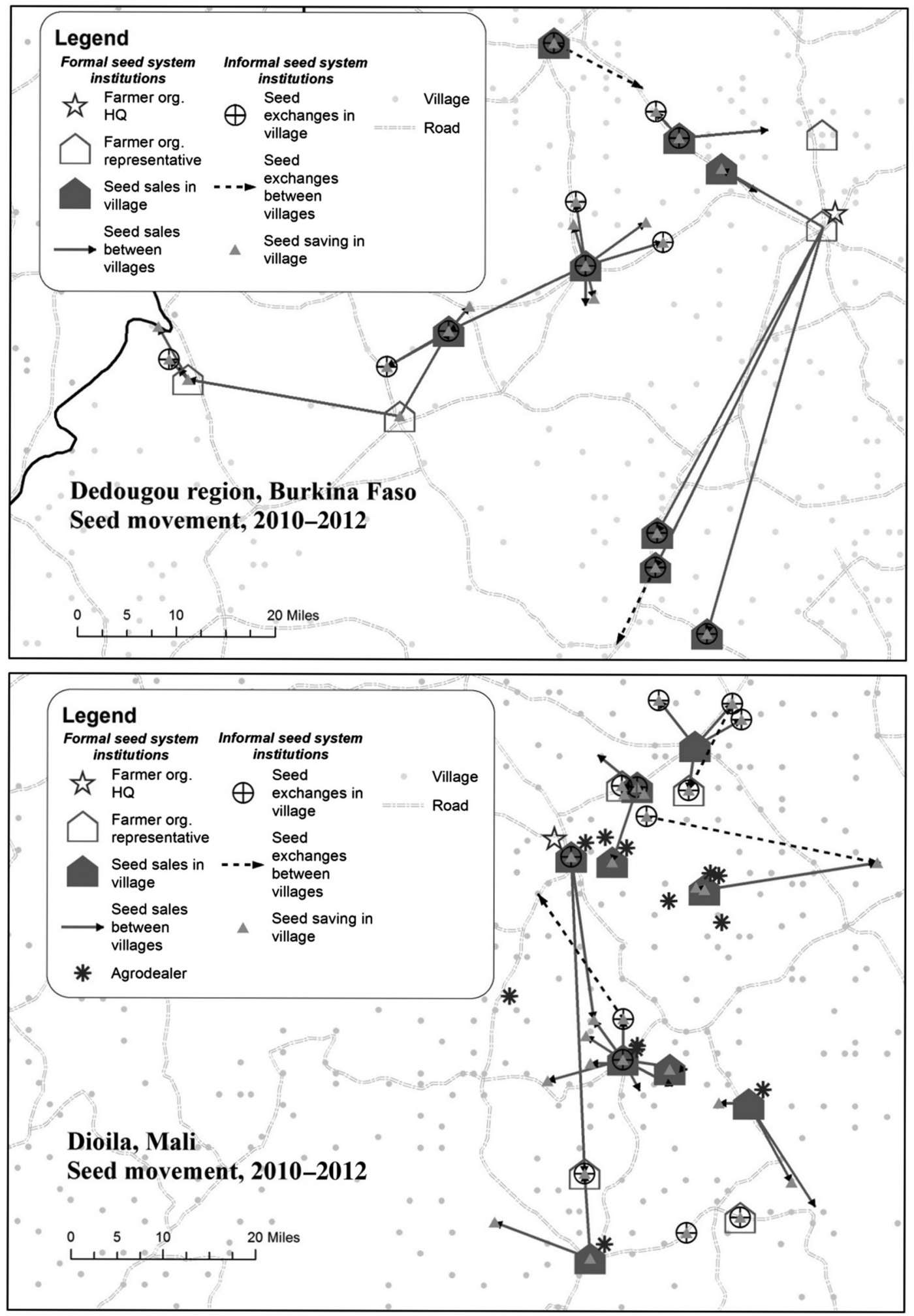

Fig. 2. Seed movement and access maps for Dedougou, Burkina Faso, and Diolia, Mali, 2010-2012. Map data layers were generated by the author out of primary data, with the exception of roads (DIVA-GIS 2013) and villages (ICRISAT 2013). Maps were created by the author in ArcGIS Suite. 
that could have been sold back to the farmer organization to be certified for further sale in the formal seed value chain, but that farmers chose to exchange for cash or in-kind outside the formal seed system.

The maps in Fig. 2 also highlight some differences between the two types of research sites. The agrodealer program that supports small private input dealers and links them to national-level private seed enterprises is much better developed in Mali than it is in Burkina Faso, and many agrodealers exist in the Diola region of Mali but none are present in the Dedougou region of Burkina Faso. The map of seed movement in Diola highlights a potential impact of agrodealers on the integration of the formal and informal seed systems. In several villages where both agrodealers and farmer organization representatives are based (usually villages that host a weekly market day), there are no reports from farmers of sharing seeds with others the following year. Many farmers who access improved variety seeds by purchasing them in one of these villages did, however, report saving seeds for their own use for the following year. The increased commercialization of seeds sales in Mali due to the presence of agrodealers in the same areas as farmer organizations that also sell seeds possibly explains the lack of seed sharing in Diola as compared with the Dedougou region of Mali. There is less need for integration between the formal and informal seed systems, as there is more opportunity to purchase seeds each year in the Dioila region because of the more diversified and established formal value chain. In addition, as more farmers experience the standardized social institutions that constitute the formal seed system, particularly embodied in the prices and relationships to extra-local seed enterprise that agrodealers bring to local markets, the less likely they are to see those institutions as compatible with those of the informal seed system.

\section{Discussion and conclusion}

As farmers have experienced the impacts of the new social institutions associated with the formal market-oriented seed systems established in Sahelian West Africa over the past 10 years, individuals and communities have begun to differentiate among these institutions and to engage with them in ways that fit local values, needs, and priorities. Farmer organizations and their seed producer members are seen as link between the formal and informal seed systems and, as seen in Figs. 1 and 2, individual and community engagement with both these local and formal social institutions expands the spatial extent of seed value chains, local seed networks, and the knowledge associated with improved varieties. Farmers note some ambivalence about this engagement, as the interconnection of formal and informal seed systems both increases access to seed and decreases local control over the values associated with seed value chains.

Seed sales by both farmer organization representatives and agrodealers provide consistent access to seeds of known quality, but access requires cash. Farmers noted both positive and negative impacts of these characteristics of formal seed systems and the institutions that constitute them. The stability and impersonal nature of accessing seeds through the formal seed system provides a type of certainty that can be missing from the social institutions of informal seed systems, which are often predicated on communal solidarity and reciprocity over the long term. There are especially interesting and unexpected gendered implications of the impersonal, formal seed system institutions, with some women reporting that their access to improved variety seeds has increased based on the ability to use cash rather than personal relationships to acquire seed.

The flip side of the impersonal nature of the formal seed system is that the only currency that can provide access to seed is cash, a scarce resource for most smallholder farmers across the Sahelian region and one that cannot be counted upon. Farmer organizations, and especially the seed producers who are members of them, are addressing this limitation by engaging exchanges of 
seed that would otherwise be certified and sold in the formal system. As many farmers note, the value of mutual support embodied in familial and communal social institutions leads seed producers, who are embedded in the same communities where seeds are being sold and are therefore trusted sources of information and resources, to provide access to some of their seed for currencies other than cash. In contrast to these representatives of farmer organizations, agrodealers are seen largely as outsiders and as discrete links in an otherwise impersonal formal seed value chain. Farmers who experience the benefits associated with formal economic exchanges discuss engaging with agrodealers on these terms, but agrodealers are not seen or interacted with by farmers as social institutions that can link across the formal and informal seed systems.

Farmers' descriptions of the varied impacts that the establishment of formal market-oriented seed systems has had on access to improved variety seeds, as well as their engagement with the new social institutions that constitute formal seed systems, suggests an appreciation for the complementary stability that comes from market exchanges and known varieties of seeds. These characteristics of formal seed systems complement the seed access that comes from engagement with the institutions of informal seed systems, which are based on kinship and communal reciprocity and an orientation toward risk that prioritizes seed saving as a means of self-sufficiency. It is especially this last observation, that agriculture is a risky and uncertain enterprise in the Sahel, that had led many farmers to engage with the new formal seed system as a means of diversification. Village-level representation of changing seed systems and the systematic documentation of seed movements in localized regions, presented in Figs. 1 and 2, reinforce these themes of diversification and integration of multiple seed systems, as farmers buy, share, and save seeds year after year. This integration of formal and informal seed systems is an unexpected outcome for marketoriented development projects, which highlight the increases in productive and economic efficiency as sufficient motivation for agricultural systems and the social institutions that support them to make a wholesale shift into the modern era. However, a pragmatic take on the goals and desirable impacts of contemporary approaches to agricultural development suggests that integration and broadening of choices is preferable to silver-bullet solutions (Louwaars and de Boef 2012).

After several years of market-oriented seed system development in Sahelian West Africa, we are seeing instead a broadening of seed systems and the social institutions that constitute them, as farmers diversify their activities and farmer organizations, in particular, emerge as an integrating social institution. Through the lens of modern market-oriented development, the integration of informal and formal seed systems might be surprising, because the persistence of informal access activities and the seeds that are accessed through them fails to maximize yield gains and economic calculations about returns on investment. However, the social institutions that constitute informal seed systems and facilitate access to many types of seeds play other roles for individuals and communities, and reflect the varied priorities that guide agricultural decision-making for farmers in many parts of the world (Richards et al. 2009). Identifying and supporting social institutions, like farmer organizations, that can encapsulate multiple values and so play a bridging role across formal and informal systems is necessary to facilitate inclusive and appropriate agricultural development projects and programs.

\section{Acknowledgements}

This research was supported by the International Crop Research Institute for the Semi-Arid Tropics (ICRISAT). The analysis was supported by the National Socio-Environmental Synthesis Center (SESYNC), which is funded by National Science Foundation Grant \#DBI-1052875. 


\section{Author contributions}

$\mathrm{KJ}$ conceived and designed the study. KJ performed the experiments/collected the data. KJ analyzed and interpreted the data. KJ contributed resources. KJ drafted or revised the manuscript.

\section{Competing interests}

The author has declared that no competing interests exist.

\section{Data accessibility statement}

All relevant data are within the paper.

\section{References}

Alene A, Yigezu Y, Ndjeunga J, Labarta R, Andrade R, Diagne A, et al. 2011. Measuring the effectiveness of agricultural R\&D in sub-Saharan Africa from the perspectives of varietal output and adoption. Conference Working Paper Number 7. Presented at the ASTI-IFPRI/FARA Conference, Accra, Ghana, 5-7 December 2011. 19 p.

Almekinders CJM, Louwaars NP, and de Bruijn GH. 1994. Local seed systems and their importance for an improved seed supply in developing countries. Euphytica, 78(3): 207-216. DOI: 10.1007/BF00027519

Badstue LB, Bellon M, Juárez X, Manuel I, and Solano AM. 2002. Social relations and seed transactions among smallscale maize farmers in the central valleys of Oaxaca, Mexico. CIMMYT Economics Working Paper 02-02, International Maize and Wheat Improvement Center, Mexico City, Mexico.

Bellon M, Anderson CL, Lipper L, Dalton T, Keleman A, and Grum M. 2010. Synthesis: markets, seed systems and crop diversity. In Seed trade in rural markets: implications for crop diversity and agricultural development. Edited by L Lipper, CL Anderson, and T Dalton. Earthscan, Sterling, Virginia. pp. 189-208.

Bentley JW, Van Mele P, and Reece JD. 2011. How seed works. In African seed enterprises: sowing the seeds of food security. Edited by P Van Mele, JW Bentley, and RG Guéi. Food and Agriculture Organization, Rome, Italy. pp. 8-24.

Berg T. 2009. Landraces and folk varieties: a conceptual reappraisal of terminology. Euphytica, 166(3): 423-430. DOI: 10.1007/s10681-008-9829-8

Biernacki P, and Waldorf D. 1981. Snowball sampling: problems and techniques of chain referral sampling. Sociological Methods \& Research, 10(1): 141-163. DOI: 10.1177/004912418101000205

Bishaw Z, and Turner M. 2008. Linking participatory plant breeding to the seed supply system. Euphytica, 163(1): 31-44. DOI: 10.1007/s10681-007-9572-6

Coffey A, and Atkinson P. 1996. Making sense of qualitative data. Sage, Thousand Oaks, California.

Coulibaly H, Bazile D, Sidibé A, and Abrami G. 2008. Seed supply systems of pearl millet and sorghum in Mali: production, diffusion and conservation of varieties. Cahiers Agricultures, 17(2): 199-202.

Creswell JW. 2007. Qualitative inquiry and research design. Sage, Thousand Oaks, California. 
Creswell JW, and Plano-Clark V. 2011. Designing and conducting mixed methods research. Sage, Thousand Oaks, California.

Dalohoun D, Van Mele P, Weltzien E, Diallo D, Guindo H, and vom Brocke K. 2011. Mali: when government gives entrepreneurs room to grow. In African seed enterprises: sowing the seeds of food security. Edited by P Van Mele, JW Bentley, and RG Guéi. Food and Agriculture Organization, Rome, Italy. pp. 65-88.

Diakité L, Sidibé A, Smale M, and Grum M. 2008. Seed value chains for sorghum and millet in Mali: a state-based system in transition. IFPRI Discussion Paper No. 00749, International Food Policy Research Institute, Washington, D.C.

DIVA-GIS. 2013. Free spatial data: roads. Digital chart of the world [online]: Available from diva-gis. org/Data.

Fortmann L (Editor). 2008. Participatory research in conversation and rural livelihoods. Wiley-Blackwell Publishing, West Sussex, UK.

Granovetter MS. 1985. Economic action and social structure: the problem of embeddedness. American Journal of Sociology, 91(3): 481-510. DOI: 10.1086/228311

Halai N. 2007. Making use of bilingual interview data: some experiences from the field. The Qualitative Report, 12(3): 344-355.

Haussmann BIG, Rattunde HF, Weltzien-Rattunde E, Traoré PSC, vom Brocke K, and Parzies HK. 2012. Breeding strategies for adaptation of pearl millet and sorghum to climate variability and change in West Africa. Journal of Agronomy and Crop Science, 198(5): 327-339. DOI: 10.1111/j. 1439-037X.2012.00526.X

ICRISAT. 2013. Village data layers. Remote Sensing Division, ICRISAT, Bamako, Mali.

ISPC. 2012. Strategic overview of CGIAR research programs. Part II: value chains and seed systems. Independent Science \& Partnership Council, CGIAR Consortium, Rome, Italy.

Jones K. 2017. Using a theory of practice to clarify epistemological challenges in mixed methods research: an example of theorizing, modeling, and mapping changing West African seed systems. Journal of Mixed Methods Research, 11(3): 355-373. DOI: 10.1177/1558689815614960

Kloppenburg J. 2010. Impeding dispossession, enabling repossession: biological open source and the recovery of seed sovereignty. Journal of Agrarian Change, 10(3): 367-388. DOI: 10.1111/j. 1471-0366.2010.00275.x

Lipper L, Dalton T, Anderson CL, and Keleman A. 2010. Agricultural markets and the sustainable use of crop genetic resources. In Seed trade in rural markets: implications for crop diversity and agricultural development. Edited by L Lipper, CL Anderson, and T Dalton. Earthscan, Sterling, Virginia. pp. 3-14.

Louwaars N, and de Boef WS. 2012. Integrated seed sector development in Africa: a conceptual framework for creating coherence between practices, programs, and policies. Journal of Crop Improvement, 26(1): 39-59. DOI: 10.1080/15427528.2011.611277

Moseley WG. 2008. Strengthening livelihoods in Sahelian West Africa: the geography of development and underdevelopment in a peripheral region. Geographische Rundschau International Edition, 4(4): 44-50. 
Ostrom E, and Ahn TK. 2001. A social science perspective on social capital: social capital and collective action. Conference paper presented at European Research Conference on Social Capital: Interdisciplinary Perspectives, Exeter, UK, 15-20 September 2001. 58 p.

Peters AM. 1973. The units of language acquisition. Cambridge University Press, New York, New York.

Pingali PL. 2010. Agriculture renaissance: making "agriculture for development" work in the 21st century. In Handbook of agricultural economics. Edited by P Pingali and R Evenson. Elsevier, Burlington, Massachusetts. Edition 1, Vol. 4, No. 1, pp. 3867-3894.

Pingali PL, and Rosegrant MW. 1995. Agricultural commercialization and diversification: processes and policies. Food Policy, 20(3): 171-185. DOI: 10.1016/0306-9192(95)00012-4

Pradhan P, Fischer G, van Velthuizen H, Reusser DE, and Kropp JP. 2015. Closing yield gaps: how sustainable can we be? PLoS ONE, 10(6): e0129487. PMID: 26083456 DOI: 10.1371/journal. pone.0129487

Pretty J, Toulmin C, and Williams S. 2011. Sustainable intensification in African agriculture. International Journal of Agricultural Sustainability, 9(1): 5-24. DOI: 10.3763/ijas.2010.0583

Richards P, de Bruin-Hoekzema M, Hughes SG, Kudadjie-Freeman C, Kwame Offei S, Struik P, et al. 2009. Seed systems for African food security: linking molecular genetic analysis and cultivator knowledge in West Africa. International Journal of Technology Management, 45(1/2): 196-214. DOI: 10.1504/IJTM.2009.021528

Scoones I, and Thompson J. 2011. The politics of seed in Africa's green revolution: alternative narratives and competing pathways. Institute of Development Studies Bulletin, 42(4): 1-23. DOI: 10.1111/j. 1759-5436.2011.00232.x

Siart S. 2008. Strengthening local seed systems: options for enhancing diffusion of varietal diversity of sorghum in southern Mali. Doctoral degree, Agricultural Communication and Extension, University of Hohenheim, Hohenheim, Germany, 184 p.

Smale M, Dembélé B, Traoré IS, Guindo O, and Konta B. 2008. Trading millet and sorghum genetic resources: women vendors in the village fairs of San and Douentza, Mali. IFPRI Discussion Paper Series No. 00746, International Food Policy Research Institute, Washington, D.C.

Small ML. 2011. How to conduct a mixed methods study: recent trends in a rapidly growing literature. Annual Review of Sociology, 37(1): 57-86. DOI: 10.1146/annurev.soc.012809.102657

Sperling L, and McGuire S. 2010. Understanding and strengthening informal seed markets. Experimental Agriculture, 46(2): 119-136. DOI: 10.1017/S0014479709991074

Teddlie C, and Yu F. 2007. Mixed methods sampling: a typology with examples. Journal of Mixed Methods Research, 1(1): 77-100. DOI: 10.1177/2345678906292430

Toenniessen G, Adesina A, and DeVries J. 2008. Building an alliance for a green revolution in Africa. Annals of the New York Academy of Sciences, 1136: 233-242. PMID: 18579885 DOI: 10.1196/annals.1425.028

Tripp R. 2001. Seed provision \& agricultural development. Overseas Development Institute, London, UK. 
Van Mele P, Bentley JW, and Guéi RG (Editors). 2011. African seed enterprises: sowing the seeds of food security. Food and Agriculture Organization, Rome, Italy.

Weiss R. 1994. Learning from strangers: the art and method of qualitative interview studies. The Free Press, New York, New York.

Weltzien E, Smith ME, Meitzner LS, and Sperling L. 2003. Technical and institutional issues in participatory plant breeding-from the perspective of formal plant breeding: a global analysis of issues, results, and current experience. CGIAR Systemwide Program on Participatory Research and Gender Analysis for Technology Development and Institutional Innovation, PPB Monograph No. 1, Centro Internacional de Agricultura Tropical (CIAT), Cali, Colombia. 208 p. 